\title{
Investigation of Heavy Metal Contents in Cow Milk Samples from Area of Merowe-Sudan
}

\author{
Mawia Hassan Elsaim ${ }^{1,2, ~ *, ~ R a s h a ~ J a m e ~}{ }^{3,4}$, Yahya Ali ${ }^{1}$ \\ ${ }^{1}$ Department of Chemistry, Faculty of Science and Technology, Merowe University of Technology, Merowe, Sudan \\ ${ }^{2}$ Department of Chemistry, College of Science, Beijing University of Chemical Technology, Beijing, China \\ ${ }^{3}$ Department of Chemistry, Faculty of Science, University of Tabuk, Tabuk, Saudi Arabia \\ ${ }^{4}$ Department of Chemistry, Faculty of Education, University of Dalaj, Dalaj, Sudan
}

Email address:

Maelsaimhu7@gmail.com (M. H. Elsaim)

${ }^{*}$ Corresponding author

\section{To cite this article:}

Mawia Hassan Elsaim, Rasha Jame, Yahya Ali. Investigation of Heavy Metal Contents in Cow Milk Samples from Area of Merowe-Sudan. American Journal of Mechanics and Applications. Vol. 8, No. 1, 2020, pp. 21-24. doi: 10.11648/j.ajma.20200801.14

Received: April 6, 2019; Accepted: May 20, 2019; Published: March 10, 2020

\begin{abstract}
Cow's milk is considered as one of responsible food sources contamination with heavy metals. The objective of the study were to assess to content of selected heavy metals in fresh cow's milk and its associated human health risks in the food chain in Sudan. Fresh cow's milk samples were collected from two dairy of Merowe city-North Sudan by using Atomic Absorption Spectrophotometer (AAS) was used for the quantitative determination of the concentration of sex heavy metals namely $(\mathrm{Cd}$, Cr,

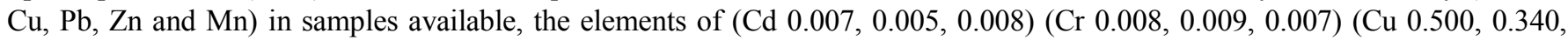

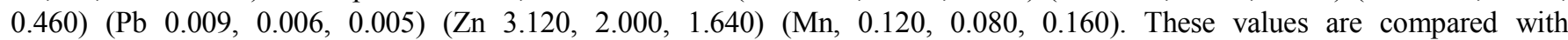
Recommended Dietary Allowance (ARD) values and also with corresponding values of different countries available in the literature our result of this paper it is co strong to meager the concentration of seven heavy metals and show an important.
\end{abstract}

Keywords: AAS, Fresh Cow's Milk, Heavy Metals, Contamination, Merowe

\section{Introduction}

It is well known that increase in industrial and agricultural processes has resulted in increased concentration of metals such as $\mathrm{Cu}, \mathrm{Zn}, \mathrm{Mn}, \mathrm{Fe}, \mathrm{Cr}, \mathrm{Ni}, \mathrm{Pb}, \mathrm{Cd}, \mathrm{Al}, \mathrm{Se}$ and $\mathrm{Hg}$ in air, water and soil. Such metals are taken in by plants and subsequently get accumulated in their tissues. Thereafter such metals get accumulated in the animals that graze on such contaminated plants and/or in the animals that drink polluted waters and/or inhale polluted air. Metals enter the human body through inhalation of polluted air, ingestion of polluted food and water or absorption through the skin [1]. Thus, large amount of these metals that are taken up by plants and animals subsequently find their way into the food chain. The scientific community is greatly concerned about the ever increasing pollution of the environment, especially about the intake of harmful metals by human beings, plants and animals.

Heavy metals are persistent contaminants is the environment that can cause serious environmental and health hazards. They are released into the environment from natural and man-made activities. Some heavy metals (like Fe) are essential to maintain proper metabolic activity in living organisms; others (like $\mathrm{Pb}$ and $\mathrm{Cd}$ ) are non-essential and have no biological role $[2,3]$. However, at high concentration, they can cause toxicity to living organisms [4].

Lead is recognized as a known neurotoxicant with major public health concern which causes both acute and chronicintoxication [5]. The toxicity may show in the form of anemia, abdominal colic, liver dysfunction, renal damage, peripheral neuropathy in adults, CNS disorders in the form of permanent brain damage in children and in case of extreme lead poisoning, convulsion followed by coma and death, might occur. Moreover, lead has a biological half-life of about 27 years in human bones [6]. Cadmium intoxication in human results in renal damage and dystrophic changes with hypercalcuria, glucosuria, proteinuria and aminoaciduria with hypertension [7], and itai disease which is characterized by 
severe pain, soft bones and death may occur as a result of renal failure [8].

\section{Martial and Methods}

\subsection{Sample Collection and Preparation}

Fresh cow's milk form three grazing areas of Merowe metropolis was collected, packed in $50 \mathrm{ml}$ bottles and stored in deep freezer at a temperature of $-20^{\circ} \mathrm{C} 20 \mathrm{ml}$ of fresh cow's milk sample was measured into beaker and $20 \mathrm{ml}$ of aqua regia was also add. This was digests by heating the content in the beaker to nearly dryness. After evaporation and cooling, $20 \mathrm{ml}$ of distilled water was add to the beaker, stirred and filtered into $50 \mathrm{ml}$ volumetric flask and filled to the mark with distilled water. It was then transferred into $50 \mathrm{ml}$ sample bottle labeled and heavy metals were determined using bulk scientific model VER3.94Cmodel Atomic Absorption Spectrophotometer.

\subsection{Data Assessment}

Was collect and ordered all data in tables the concentration of some fresh cow's milk sample in ppm yielding positive results for the occurrence of microelements were transformed in to concentration in $\mathrm{mg} / \mathrm{l}$.

\subsection{Chemical and Reagents}

All reagents were used of analytical grade deionized water were used to prepare all solution. Nitric acid $65 \%$ (Spectrosol, BDH, and England) and hydrogen peroxide 30\% (Eurostar Scientific LTD), and concentrated hydrochloric acid. Double distilled water (deionized water) was used for the preparation of all solution. All samples were stored in plastic bottles.

\subsection{Samples Collection}

The polyethylene sampling bottle were soaked in $20 \%$ $\mathrm{HNO}_{3}$ for 24 hours and rinsed with deionised water before collection of raw milk in order to avoid possible contamination. The udder of each cow was washed with distilled water before milking. The three samples of fresh cow's milk of different area were collected from various locations of Merowe and Karrim north Sudan. The study was selected based on the dependence of farmers on lives stock production mainly from cows is representative of the whole country as it is considered milk belt in Sudan. A milk sample of $100 \mathrm{ml}$ was collected during morning milking time from each cow and homogenized, and were kept in an ice box. The samples were transported to laboratory and immediately kept a deep freeze $\left(-20^{\circ} \mathrm{C}\right)$ until microwave digestion was carried out.

\subsection{Sample Preparation}

A $5 \mathrm{ml}$ each aliquot of milk sample was transferred into in $100 \mathrm{ml}$ volumetric flask, add $50 \mathrm{ml}$ of $24 \%$ (w/v) TCA and dilute to volume with deionized water Shake the samples at 5min intervals for $30 \mathrm{~min}$ and filter. Transfer a5-ml aliquot of the filtrate to a50ml volumetric flask, add $1 \mathrm{ml}$ of $5 \%(\mathrm{w} / \mathrm{v})$ lanthanum solution, and make to volume with deionized water.

Table 1. Instrumental operating condition for determination of heavy metals in milk sample.

\begin{tabular}{lllll}
\hline $\begin{array}{l}\text { Heavy } \\
\text { Metals }\end{array}$ & $\begin{array}{l}\text { Wave length } \\
(\mathbf{n m})\end{array}$ & $\begin{array}{l}\text { SlitWidth } \\
(\mathbf{n m})\end{array}$ & $\begin{array}{l}\text { LampCurrent } \\
(\mathbf{m A})\end{array}$ & $\begin{array}{l}\text { SampleEnergy } \\
(\mathbf{e V})\end{array}$ \\
\hline $\mathrm{Cd}$ & 228.8 & 0.7 & 2.0 & 3.317 \\
$\mathrm{Cr}$ & 357.9 & 0.7 & 2.0 & 3.567 \\
$\mathrm{Cu}$ & 324.8 & 0.7 & 1.5 & 3.884 \\
$\mathrm{~Pb}$ & 283.3 & 0.7 & 3.0 & 2.470 \\
$\mathrm{Zn}$ & 213.9 & 0.7 & 2.0 & 3.148 \\
\hline
\end{tabular}

\section{Results and Discussion}

Heavy metals contents varies widely due to many factors such as difference between species, characteristic of manufacturing practices and possible contamination from equipment's during the process among the sex elements analyzed. This could be as a result of low pollution to these metals in the study areas.

Table 2. mean concentration of heavy metals in cow milk samples collected from Merowe.

\begin{tabular}{lllllll}
\hline & \multicolumn{6}{l}{ Cow milk concentration of Heavy metals $(\mathbf{m g} / \mathbf{k g})$} \\
\cline { 2 - 7 } & Cd & Cr & Mn & Cu & Pb & Zn \\
\hline A & 0.007 & 0.008 & 0.120 & 0.500 & 0.009 & 3.120 \\
B & 0.005 & 0.009 & 0.080 & 0.340 & 0.006 & 2.00 \\
C & 0.008 & 0.007 & 0.160 & 0.460 & 0.005 & 1.640 \\
\hline
\end{tabular}

\subsection{Cadmium Concentration}

The cadmium concentration in three products samples analyzed was lower than allowed limit $(5 \mathrm{mg} / \mathrm{kg})$. The could be as result of low pollution to this metal in the study regular absorption of cadmium causes damage to the proximal renal tubules and calcium phosphorus glucose amino acid and small peptides are loss in the urine once calcium accumulates in tissues it cannot be removed safely by chelation therapy without causing kidney damage cadmium affects calcium metabolism and skeletal changes resulting from calcium loss and ends in adecrease bone mineral density $[9,10]$.

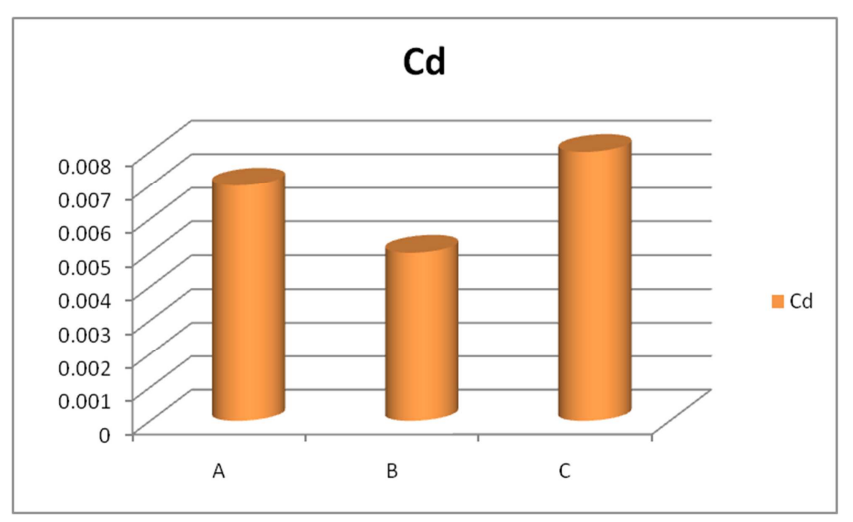

Figure 1. Cadmium concentration. 


\subsection{Chromium Concentration}

The concentration of chromium in the milk sample mean $(0.008,0.009,0.007)$ this show that the cows milk in the study area is rich in chromium although $\mathrm{Cr}$ and other microelements are essential to maintain the metabolic systems of human body they can lead to poisoning at higher level [3].

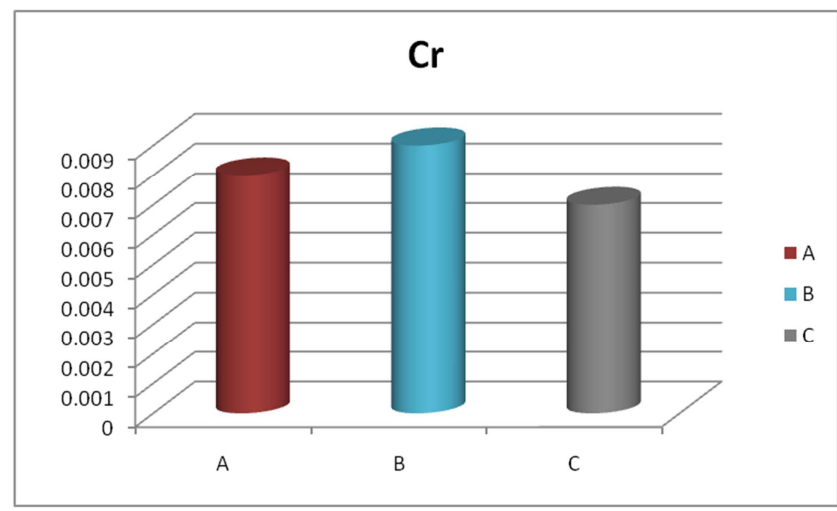

Figure 2. Chromium concentration.

\subsection{Manganese Concentration}

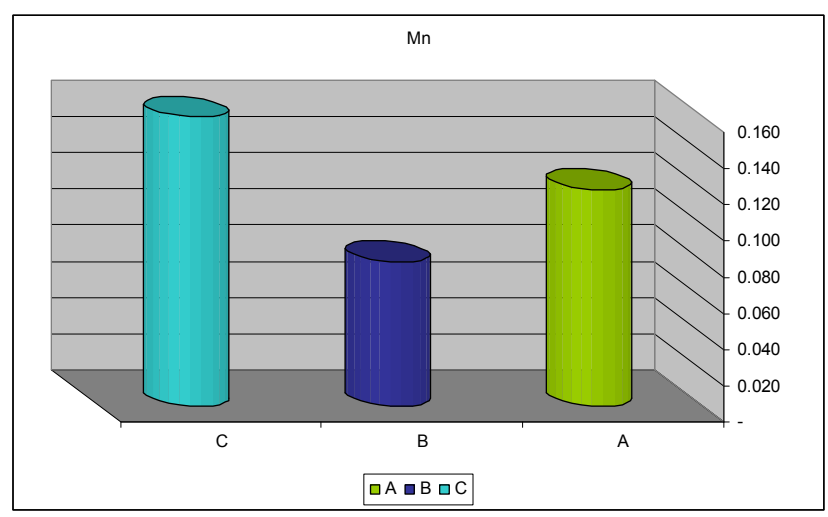

Figure 3. Manganese concentration.

Only a few data on the milk concentration of Mn have been reported. The concentration obtained range between are $(0.120,0.080,0.160) \mathrm{mg} / \mathrm{l}$ in this study is below the accepted limit recommended dietary value of.

\subsection{Copper Concentration}

The possible contamination of milk with copper can occur from animal feed higher copper content in water and also from copper bearing and copper alloys used in equipment contamination of cows milk with copper from brass containers has been cited as the major environmental factor in the etiology of Indian childhood cirrhosis [11, 12]. The concentration of $\mathrm{cu}$ in this research work occur between $(0.500,0.340,0.460)$ these are below the recommended dietary value stipulated by NRC, 1989. This indicates that cows milk of this study area is poor source of copper. Copper is essential trace element that plays a vital role in the physiology of animals for foetal growth and early post-natal development. Excess copper in the body leads to Wilsons disease which characterized by deficient of ceruplasmin.



Figure 4. Copper concentration.

\subsection{Leadconcentration}

The main sources of lead pollution in the environment include effluents and emissions from industries emissions from vehicles running on leaded petrol, the smoke and dust emissions of coal and gas fired power stations use of lead sheets by roofers as well as the use of paints and anti-rust agents contamination by lead of foodstuffs is caused dy the soldered seams of cans and the soldered closures of condensed milk cans the metal caps of wine bottles and also by lead pipes used in drinking water systems. Lead has concentration rang between $(0.009,0.0060 .005) \mathrm{mg} / \mathrm{L}$ which is above the recommended dietary allowance for adult which is $0.02 \mathrm{mg} /$ day. This could be ascribed to the fact that kawo is a cosmopolitan area where a lot human activities were taken part. Lead has no beneficial biological function and is known to accumulate in the body. Lead exposure can cause adverse health effects, especially in young children and pregnant women, since lead is a neurotoxin that permanently interrupts normal brain development.

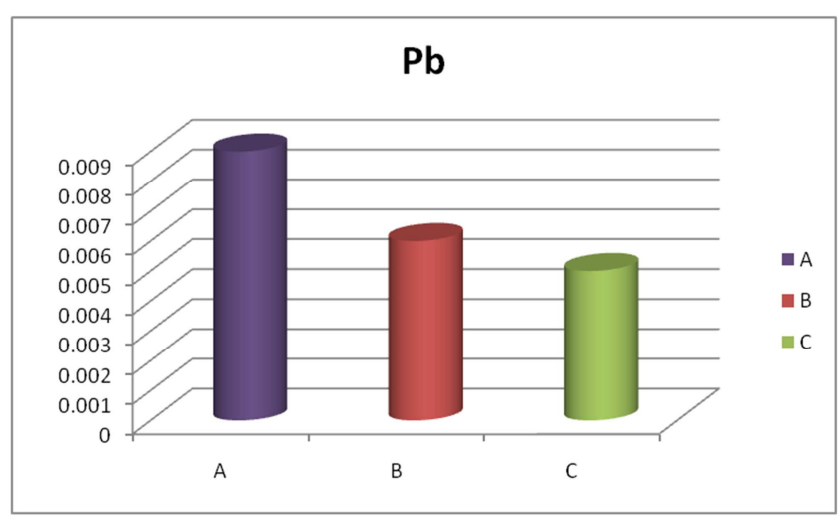

Figure 5. Lead concentration.

\subsection{Zinc Concentration}

In this study was observed in all samples analyzed highest level 3.120 of which was found in the sample from Merowe. This concentration was higher than was observed in Sokoto Metropolis, Nigeria and two-fold lower than [13]. Zinc plays an important role in the immune system but excessive 
absorption of zinc suppresses copper and iron absorption which results in decrease in erythrocyte the concentration of $\mathrm{Zn}$ is $(3.120,2.00,1.640)$.

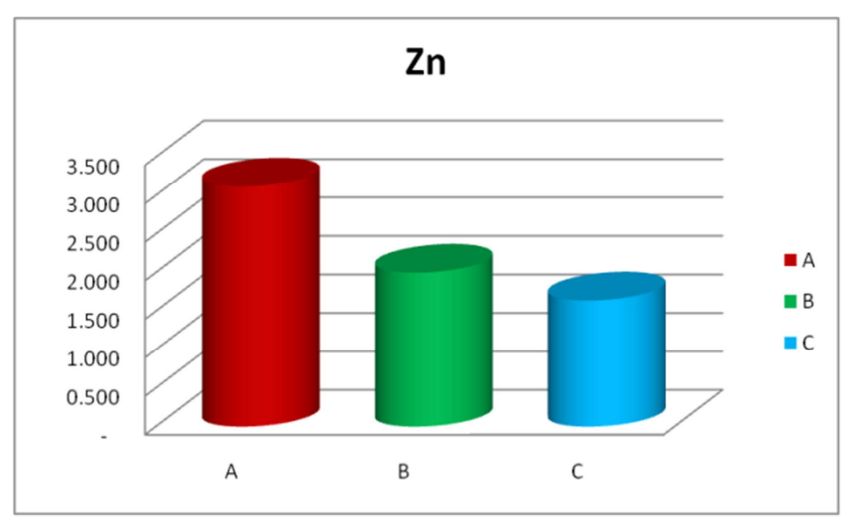

Figure 6. Zinc concentration.

Table 3. Comparison of the elemental concentration $(\mathrm{mg} / \mathrm{kg})$ of fresh cow's milk in Sudan.

\begin{tabular}{lllllll}
\hline Country & $\mathbf{C d}$ & $\mathbf{C r}$ & $\mathbf{C u}$ & $\mathbf{P d}$ & $\mathbf{Z n}$ & Reference \\
\hline Japan & 1.0 & --- & 100.0 & 50.0 & 3000.0 & {$[14]$} \\
Germany & 0.1 & ---- & 49.9 & 5.5 & 3730.0 & {$[15]$} \\
India & 0.1 & 55.2 & 56.0 & 1.6 & 3100.0 & {$[16,17]$} \\
Spain & ---- & 33.9 & 9.7 & 49.3 & 1419.3 & {$[18]$} \\
Poland & 15.0 & 38.0 & 90.0 & 20.0 & 3770.0 & {$[19]$} \\
USA & 9.7 & 29.1 & 19.4 & 34.0 & 2235.2 & {$[20]$} \\
Sudan & ---- & ---- & 14.03 & ---- & 139 & Present study \\
\hline
\end{tabular}

$\mathrm{NR}=$ not reported.

Our results are comparable with values identified by other authors. Table 3 presents a comparison of our values with concentration established in other studies.

\section{Conclusion}

Differences in the concentration of major and minor chemical elements in cow milk depend on many circumstances which are related to geographical location, soil type, nutrition, breed, age, lactation period, geographical location, mineral status of animals. However, sex heavy metals concentration in cow's milk from polluted areas are high compared from non-polluted areas. These differences can be detected even in milk product such as cheese and eggs. Our results confirm attention must be paid to circumstances entailing continuous emission of heavy metals elements into the environment. The concentration of $\mathrm{Cd}, \mathrm{Cr}$, $\mathrm{Cu}, \mathrm{Pb}, \mathrm{Mn}$ and $\mathrm{Zn}$ were analyzed in cow milk samples collected from three areas ofMerowe of Sudan the result revealed that $\mathrm{Cd}, \mathrm{Cr}, \mathrm{Pb}, \mathrm{Cu}$ andZn were detected in all sample and found to be above the stipulated limits of recommended dietary allowance (nrc19989).

\section{References}

[1] A. oskarsson, A. schutz, Skerfving, ip, hallen, j. Lagerkvist arch, (1996) environ health 51.234.
[2] Ayar, A, sert, D, akin, n, (2009), the trace metal levels in milk and dairy products consumed in middle Anatolia turkey environ monitor assess $152 ; 1.12$.

[3] Qin, 1, wang x, li w. tongx, tong w (2009) minerals and heay metals in cow s milk in china and japan, journal of health science $55 ; 300-305$.

[4] Li Y, McCrory Df, powel Jm, saam H, Jackson smith D (2005) A survery of selected heavy metal concentration in Wisconsin dairy feeds j dairy science 88, 2911-2922.

[5] Gossel, T. A. Bricker, J. D (1990) metals in principles of clinical toxicology, $2^{\text {nd }}$ ed raven press new york pp. 162-192.

[6] Shibamoto, T, Bjeldanes, I. (1993) introduction to food toxicology academic press inc Harcourt brace company new york food science and technology international series.

[7] Graceny, M, Collins. D (1992) meat hygiene $9^{\text {th }}$ ed, ELBS with bailliertindell London UK chap 10 pp 205-221.

[8] Peter, O. (1993) environmental chemistry 2ed champanand hall press, new york pp 203-221.

[9] Nnadozie, C, ubirninyauri u a Muhammad c (2014) assessment of some dairy products sold in sokoto metropolis Nigeria inter J Adv. res in chem SCI (c10), 31-37.

[10] Nordberggf, G. (2004); cadmium and health in the 21 centaury historical remarks atrend for the future bio metals. 17 (5); 485489).

[11] Mitchell, G, E (1981) trace metal level in queensland dairy products austj. dairytechnol, 6; 70-73.

[12] Yuzbasi, N, Sezgin, E. Yildrim, M. Yildrim, N, (2003 (Survey of lead, Cadmium, iron and copper ans zinc in kasarcheese, Food chemistry 20 (5): 464-469.

[13] ATSDR (2011), Agency 4 Toxic Substance and Disease Registry. Lead Toxicity. How are people Exposed to lead ? Achieved prom The Original.

[14] Cortes, E. Das, H. A. Tarafdar, D. andVasconcellos, B. A. Toxic heavy Meatals and other Trace Elements in Foodstuff from 12 different countries Biological Trace Element Research, 20; 415_422 (1994).

[15] Ostapezuk, P. Valenta, P. Rutzel, H. and Nurnberg, H. W. Determination of Heavy Metal in Environmental Sambles. Sci. of total Environ, 60: 1_16 (1987).

[16] Tripathi, R. M.: Raghunath, R. and Krishnamoorrthy, T. M. Dietary intake of heavy metals in Bombay city, India, Sci. of Total Environ. 208: 49_159 (1997).

[17] Krishnamoorty, T. M. and Tripathi, R, M. Measurements and Modeling in Environmental pollution, BARC News Letter. India, 176: 3_12 (1998).

[18] Schuhmacher, M. Domingo, J L, Corbella, J. Dietary intake of Copper Choromium and Zinc in Tarrangona province. Spain. Sci. of total Environ. 132; 3-10 (1983).

[19] Bulinski, R. Bloniarz. J. and Libelt, B. Trace Element content in milk and some milk products. Bromat. Chem. Toksykol. XXV: 327-331 (1992).

[20] Lopez, A. Collins, W. F. and Williams, H. L. Essential Elements in Raw and Pasteurized Cow and Goat Milk, J. Dairy Sci. 68; 1878-1886 (1995). 